\title{
Pertimbangan Anestesia untuk Pasien dengan Deep Brain Stimulator Tertanam yang Menjalani Prosedur Diagnostik dan Pembedahan
}

\author{
Dhania A. Santosa*), Marsudi Rasman**), Hamzah*), Siti Chasnak Saleh") \\ ${ }^{*}$ Departemen Anestesiologi dan Reanimasi Fakultas Kedokteran Universitas Airlangga-RSUD Dr. Soetomo \\ Surabaya, ${ }^{* *}$ Departemen Anestesiologi dan Terapi Intensif Fakultas Kedokteran Universitas Padjadjaran-RSUP \\ Dr. Hasan Sadikin Bandung
}

\begin{abstract}
Abstrak
Deep brain stimulation (DBS) akhir-akhir ini sering digunakan untuk penyakit Parkinson dan kelainan pergerakan lainnya. DBS sendiri merupakan suatu stimulator yang ditanam pada nukleus dalam di otak dan disambungkan dengan pembangkit pulsasi yang ditanam di bawah klavikula. Sebagai konsekuensinya, ahli anestesiologi akan lebih sering menghadapi pasien dengan sistem DBS tertanam dalam tubuh mereka untuk menjalani prosedur diagnostik dan pembedahan. Anestesia pada pasien-pasien ini memerlukan perhatian khusus karena adanya potensi interferensi antara neurostimulator dan alat-alat lainnya yang dapat menbahayakan pasien. Oleh karenanya penting bagi ahli anestesi untuk memahami hal-hal khusus pada pasien dengan deep brain stimulator tertanam yang menjalani tindakan diagnostic maupun pembedahan. Panduan mengenai hal-hal yang perlu diperhatikan oleh ahli anestesi pada pasien seperti ini masih sangat kurang dan masih sangat bergantung pada laporan kasus atau panduan yang berasal dari pabrik pembuatnya. Tujuan penulisan artikel ini adalah untuk memberikan gambaran singkat mengenai sistem DBS dan penanganan anestesi pada pasien dengan alat DBS tertanam.
\end{abstract}

Kata kunci: Deep brain stimulation, pertimbangan anestesia, pembedahan

JNI 2019;8 (1): 60-71

\section{Anesthesia Considerations in Patients with Implanted Deep Brain Stimulator undergoing Diagnostic and Surgery Procedures}

\begin{abstract}
Deep brain stimulation (DBS) has become an increasingly common treatment for Parkinson's disease and other movement disorders. DBS consist of implanted stimulator at deep nuclei of the brain and, connected to a pulse generated which is implanted under clavicle. Consequently, anesthesiologists will increasingly encounter patients with implanted DBS system facing diagnostic and surgery procedures. Anesthesia management in such patients requires specific considerations due to the possible interference between neurostimulator and other devices which are potentially harmful to the patient. Therefore, it is important for anesthesiologists to understand specific issues in patients with implanted deep brain stimulator undergoing surgery and other diagnostic procedures. Guideline on these specific issues is very limited and highly relies on case report and manufacturer's manual. The purpose of this review is to provide brief overview on DBS system and anesthesia considerations in patients with implanted DBS
\end{abstract}

Key words: Anesthesia considerations; deep brain stimulation, surgery

JNI 2019;8 (1): 60-71 


\section{Pendahuluan}

Deep brain stimulation (DBS) merupakan pilihan terapi yang efektif untuk pasien dengan gangguan pergerakan, dan sejumlah pasien dengan tremor atau penyakit Parkinson diterapi dengan teknologi ini. ${ }^{1}$ Oleh karenanya, ahli anestesiologi akan lebih sering menghadapi pasien dengan sistem DBS tertanam pada tubuh mereka di kamar operasi dan ruang radiologi. Kebanyakan ahli anestesiologi sudah mengenal dengan baik penanganan anestesi pada pasien dengan alat elektronik jantung yang ditanam dalam tubuh dan panduan praktis untuk hal ini telah banyak dikeluarkan oleh berbagai macam organisasi. Namun demikian, terdapat sedikit informasi mengenai penanganan anestesi pasien dengan neurostimulator tertanam dan kebanyakan data didapatkan dari laporan kasus dan lembar informasi pabrik pembuat alat. Tujuan tulisan ini adalah untuk memberikan gambaran singkat mengenai sistem DBS dan penanganan anestesi pada pasien dengan alat DBS tertanam. ${ }^{1}$

\section{Deep Brain Stimulation (DBS)}

Pembedahan saraf stereotaktik fungsional telah berkembang pesat dalam waktu 10 tahun terakhir. Khususnya, deep brain stimulation (DBS) saat ini adalah terapi efektif untuk penyakit Parkinson. Mekanisme kerja persisnya neurostimulasi masih belum jelas. Namun demikian, setelah sukses awal pada pasien dengan penyakit Parkinson, indikasi dan penerapan DBS telah meluas ke kelainan lainnya di antaranya tremor, distonia, nyeri kronis dan gangguan psikiatri. Dengan makin bertambahnya pasien dengan DBS, makin besar pula kemungkinan ahli anestesiologi untuk berhadapan dengan pasien dengan DBS menjalani pembedahan atau prosedur di luar penanaman DBS itu sendiri. Hal ini menuntut ahli anestesiologi untuk memahami potensi interaksi teknis alat DBS dan tindakan-tindakan antisipatifnya. ${ }^{1}$

\section{Definisi}

Deep Brain Stimulation (DBS) merupakan pilihan terapi yang efektif untuk pasien dengan gangguan pergerakan, dan makin banyak pasien dengan tremor atau penyakit Parkinson juga diterapi dengan teknologi ini. ${ }^{1}$ Prosedur DBS meliputi pemasangan elektrode pada nukleus dalam pada otak, dengan target yang umum adalah globus pallidus internus (GPi) dan nukleus subthalamikus (STN). Prosedur ini terdiri dari dua bagian yaitu pemasangan elektrode dan kemudian internalisasi kabel-kabel penghubung dan pacemaker. Prosedur ini dapat dilakukan dalam satu hari pembedahan yang dibagi menjadi dua bagian prosedur. ${ }^{2}$

\section{Indikasi}

Penggunaan DBS pertama kali dilaporkan pada tahun 1987 pada pasien dengan penyakit Parkinson predominan tremor. ${ }^{2}$ Teknologi ini membawa revolusi bagi penanganan pasien dengan gangguan pergerakan seperti tremor, distonia dan penyakit Parkinson. Keunggulan DBS dibanding pembedahan ablatif (misalnya thalamotomy dan pallidotomy) di antaranya reversibilitas, pengaturannya fleksibel dan profil keamanan yang dimilikinya. Sampai saat ini, penggunaan DBS telah digunakan untuk penanganan pasien dengan tremor esensial, juga pasien dengan distonia atau gangguan obsesif komplusif., ${ }^{3,4}$ Penelitian yang sedang berjalan menunjukkan kemungkinan keuntungan DBS untuk beberapa kelainan di antaranya epilepsi, nyeri kronis, depresi mayor, anoreksia nervosa dan penyakit Alzheimer. ${ }^{3,4}$

\section{Sistem DBS}

Sistem DBS saat ini terdiri dari satu atau lebih elektrode silinder (yang masing-masing terdiri dari kontak multipel) ditanam pada suatu target yang telah direncanakan sebelumnya pada parenkim otak, generator denyut yang dapat ditanam (implantable pulse generator - IPG) yang dimasukkan di bawah klavikula dan kabel yang menghubungkan elektrode dengan IPG. Sistem ini mengirimkan rangsangan ke elektrode (secara unilateral atau bilateral) pada amplitudo, lama denyut dan frekuensi yang sudah diatur sebelumnya. ${ }^{3}$ Pasien dengan insersi elektroda bilateral mungkin memiliki dua IPG atau satu IPG dengan dua saluran yang memungkinkan kontrol independen terhadap kedua elektrode dari satu generator. Setelah dipasang, dokter yang bertanggungjawab dapat mengatur sistem secara nirkabel dengan alat kontrol genggam. 
Klinisi dan pasien memiliki alat pemrogram yang terpisah. Bergantung pada pabrik pembuat, pemrogram pasien memungkinkan pasien untuk melakukan fungsi-fungsi dasar seperti memeriksa umur neurostimulator dan baterai pemrogram, menyalakan atau mematikan neurostimulator dan menyesuaikan pengaturan terapi dalam batas yang telah diatur oleh Dokter. Sebagai tambahan terhadap fungsi-fungsi ini, pemrogram memungkinkan Klinisi untuk masuk dan memeriksa profil pasien dan informasi mengenai sistem, mengatur parameter stimulasi, melakukan pengukuran impedansi elektroda dan mengatur batasan kontrol pasien. ${ }^{3,4}$

\section{Perkembangan dalam teknologi sistem DBS}

Sistem DBS dapat dikendalikan melalui tegangan atauarus. SistemDBSyanglebihawaldikendalikan melalui tegangan dan telah dipostulasikan bahwa sistem ini menghantarkan sejumlah arus yang bervariasi sesuai dengan perubahan yang dipicu elektrokimia pada impedansi elektroda pada hubungan otak-elektroda. ${ }^{1}$ Sistem yang lebih baru dan dikontrol dengan arus memberikan rangsangan arus yang konstan, yang mungkin secara klinis lebih efektif dibanding dengan sistem yang lebih lama dan dikontrol dengan tegangan. ${ }^{5}$ Selain itu, alat DBS dapat diatur untuk memberikan rangsangan unipolar atau bipolar. Pada unipolar, elektroda aktif ditetapkan sebagai katoda dan IPG ditetapkan sebagai anoda. Sebaliknya, rangsangan bipolar dihasilkan ketika setidaknya satu dari empat elektroda pada sistem DBS berfungsi sebagai katoda dan setidaknya satu lainnya berfungsi sebagai anoda. Sistem DBS yang lebih baru juga memberikan pilihan untuk IPG yang dapat diisi daya ulang, yang dapat memperpanjang usia dan pada akhirnya memerlukan lebih sedikit intervensi bedah untuk mengganti IPG. ${ }^{1}$

\section{Perbedaan DBS dengan Cardiac Implantable Electronic Device (CIED)}

CIED termasuk cardiac pacemaker dan implantable cardioverter-defibrillator (ICD). Sistem pacemaker jantung umumnya lebih rumit dan canggih dibanding neurostimulator. Komponen dasar pacemaker jantung serupa dengan sistem DBS dalam hal pacemaker terdiri dari elektroda (1-3 sandapan) yang ditanam pada endocardium atau epikardium, sumber energi (baterai litium-iodin) dan kabel yang menghubungkan sandapan ke baterai. Fungsi utama pacemaker jantung adalah menghantarkan arus yang mencapai ambang batas untuk membangkitkan depolarisasi otot jantung. Ambang batas ditentukan oleh pengaturan ampitudo dan lama denyut serta impedansi sandapan daripada alat. ${ }^{1}$ Tabel 1 merangkum perbedaan antara DBS dan CIED.

\section{Pertimbangan anestesia untuk pasien dengan alat $D B S$}

Pertimbangan utama dalam terapi perioperatif pasien dengan sistem DBS di antaranya kondisi medis yang menyebabkan perlunya pemasangan DBS, potensi terjadi gangguan elektromagnetik dengan sistem DBS (misalnya penggunaan elektrokauter dan magnetic resonance imaging [MRI]) dan evaluasi pasca bedah pasien dan alat. Selain itu, beberapa hal yang perlu menjadi perhatian pada penilaian pra bedah pasien dengan alat DBS di antaranya mengerti indikasi awal pemasangan DBS, sudah berapa lama dipasang dan efek alat terhadap tingkat keparahan gejala. Selain itu, mengingat DBS merupakan terapi untuk penyakit Parkinson refrakter, pasien umumnya berusia lanjut dengan riwayat penyakit dan komplikasi yang panjang. Pasien mungkin mengalami kesulitan berkomunikasi karena parahnya penyakit Parkinson yang dialaminya. ${ }^{8}$ Tabel 2 menjabarkan penanganan anestesi perioperatif pasien dengan alat DBS yang menjalani pembedahan.

\section{Pertimbangan pra bedah}

Perawatan pasien dengan DBS yang menjalani pembedahan atau prosedur tertentu dimulai dengan evaluasi pra anestesi yang bertujuan tidak hanya untuk memastikan kenyamanan dan keamanan pasien tetapi juga mencegah pembatalan yang tidak perlu. Semua pasien dengan DBS umumnya memiliki personel yang khusus mengatur DBS mereka, seringnya adalah ahli saraf atau ahli bedah saraf yang menanam alat tersebut, yang secara rutin mereka temui. Sebelum evaluasi pra anestesi, pasien harus dilihat oleh pengatur DBS primer mereka atau 
Tabel 1. Perbedaan antara Neurostimulator dan Cardiac Implantable Electronic Devices (CIED)

\begin{tabular}{|c|c|c|}
\hline Karakteristik & Neurostimulator & CIED \\
\hline \multicolumn{3}{|l|}{ Aspek teknis } \\
\hline Mekanisme Kerja & $\begin{array}{l}\text { Memberikan rangsangan } \\
\text { konstan pada daerah target }\end{array}$ & $\begin{array}{l}\text { Parameter program dapat diatur berdasarkan } \\
\text { umpan balik elektrik dari sandapan }\end{array}$ \\
\hline Frekuensi stimulasi & Lebih tinggi (di atas $100 \mathrm{~Hz}$ )6 & Lebih rendah \\
\hline Konsumsi Arus & $\begin{array}{l}\text { Lebih tinggi (sampai dengan } \\
25 \mathrm{~mA} \text { ) karena frekuensi } \\
\text { rangsangan yang lebih tinggi. } \\
\text { Lebih sering penggantian } \\
\text { baterai }\end{array}$ & Lebih rendah (sekitar $10 \mathrm{mcA}) 1$ \\
\hline Dapat dimatikan & $\begin{array}{l}\text { Dapat dimatikan untuk } \\
\text { menghemat usia baterai }\end{array}$ & Tidak dapat dimatikan \\
\hline $\begin{array}{l}\text { Efek electromagnetic } \\
\text { interference (EMI) }\end{array}$ & $\begin{array}{l}\text { EMI berpotensi berefek pada } \\
\text { fungsi neurostimulator dan } \\
\text { menyebabkan bahaya pada } \\
\text { pasien }\end{array}$ & $\begin{array}{l}\text { EMI berpotensi berefek pada fungsi CIED dan } \\
\text { membahayakan pasien }\end{array}$ \\
\hline Elektokauter & $\begin{array}{l}\text { Kewaspadaan pada penggunaan } \\
\text { elektrokauter didiskusikan pada } \\
\text { Tabel } 4\end{array}$ & $\begin{array}{l}\text { Kewaspadaan pada penggunaan elektrokauter } \\
\text { serupa dengan neurostimulator kecuali } \\
\text { pacemaker tidak dapat dimatikan } 7 \\
\text { Pacemaker sebaiknya diatur pada asynchronous } \\
\text { pacing mode pada pasien yang bergantung } \\
\text { pacemaker dan algoritme khusus sebaiknya } \\
\text { dimatikan }{ }^{7} \\
\text { Fungsi antitakiaritmia pada ICD harus } \\
\text { dihentikan }\end{array}$ \\
\hline $\begin{array}{l}\text { Magnetic Resonance } \\
\text { Imaging (MRI) }\end{array}$ & $\begin{array}{l}\text { Aman di bawah kondisi } \\
\text { tertentu. Didiskusikan lebih } \\
\text { lanjut pada bagian MRI }\end{array}$ & Secara umum merupakan kontraindikasi \\
\hline Efek magnet eksternal & $\begin{array}{l}\text { Dapat digunakan untuk } \\
\text { mematikan model } \\
\text { neurostimulator yang lebih } \\
\text { lama dengan saklar magnetis. } \\
\text { Model neurostimulator yang } \\
\text { lebih baru dikendalikan dengan } \\
\text { pemrogram jarak jauh }\end{array}$ & $\begin{array}{l}\text { Respons pacemaker terhadap aplikasi magnet } \\
\text { bergantung pada pabrik pembuat, pemrogram dan } \\
\text { usia baterai yang tersisa. Beberapa pacemaker } \\
\text { tidak berespons terhadap magnet }{ }^{7} \\
\text { Aplikasi magnet pada ICD sering menghentikan } \\
\text { fungsi antitakiaritmia. Beberapa ICD tidak } \\
\text { berespons terhadap magnet dan beberapa tidak } \\
\text { berfungsi permanen karena magnet. } \\
\text { Secara umum disarankan untuk menyesaikan } \\
\text { program pacemaker dan menghentikan fungsi } \\
\text { antitakiaritmia ICD dengan pemrogram }{ }^{7}\end{array}$ \\
\hline Efek disfungsi alat & Tidak mengancam jiwa & $\begin{array}{l}\text { Mengancam jiwa. Mungkin memerlukan } \\
\text { temporary pacing (transkutan tau transvena) atau } \\
\text { defibrilasi/kardioversi eksternal }\end{array}$ \\
\hline
\end{tabular}

Dikutip dari Yeoh TY, Manninen P, Kalia SK, Venkatraghavan L. Anesthesia considerations for patients with an implanted deep brain stimulator undergoing surgery: a review and update. J Can Anesth 2017; 64: 308-9.

wakil pembuat alat untuk konsultasi mengenai alat mereka, di antaranya untuk memastikan usia baterai dan integritas serta pengaturan alat tersebut. Pembuat, model dan nomor DBS harus diperhatikan; sering pasien sudah punya selembar kartu spesifik untuk informasi ini. Hal ini akan mempermudah komunikasi efektif dengan wakil pembuat bila dibutuhkan dalam kondisi darurat. 
Selain dari itu, pengatur primer DBS harus diberitahu mengenai pembedahan yang akan dihadapi pasien sehingga dapat memberikan informasi mengenai alat DBS, apakah dapat atau tidak dapat menyesuaikan dengan pertimbanganpertimbangan perawatan perioperatif, membantu dalam koordinasi perioperatif alat DBS dan mengkoordinir perubahan dosis obat bila diperlukan bila DBS harus dinonaktifkan sementara. Komunikasi di antara anggota tim harus dilakukan untuk memastikan keberlangsungan perawatan. ${ }^{8}$ Pada periode pra bedah, pasien dengan alat DBS dijadwalkan untuk pembedahan elektif harus diperiksa di klinik pra anestesi, khususnya karena kondisi medis yang mendasari mungkin menyebabkan adanya pertimbangan khusus. Sebagai contoh, pasien dengan penyakit Parkinson, distonia atau epilepsi, masingmasing memiliki pertimbangan perioperatif unik tersendiri. ${ }^{89}$ Karena banyaknya kewaspadaan yang harus diingat ketika merawat pasien dengan DBS, evaluasi pra anestesi adalah kunci untuk memastikan keamanan dan kenyamanan pasien selama pembedahan atau prosedur. Sebuah daftar tilik (tabel) dapat membantu memastikan informasi yang diperlukan telah didapat. ${ }^{1}$

\section{Pertimbangan selama pembedahan}

Rekomendasi selama pembedahan adalah menonaktifkan alat DBS selama pembedahan. Namun demikian durasi penonaktifan alat ini harus dibatasi untuk meminimalisir tingkat keparahan gejala Parkinson setelah emergence. Bila pasien mengalami gejala mendasar yang berat, mungkin paling baik mematikan alat setelah induksi anestesi umum. Bila dimatikan sebelum induksi, pasien mungkin mengalami diskinesia yang menyebabkan intervensi seperti intubasi endotrakea dan akses vaskular lebih sulit. Perhatian khusus pada saat pemosisian pasien, karena manipulasi leher dapat mengganggu dan mungkin merusak sandapan alat DBS. Alat harus dinyalakan kembali sebelum emergence tidak hanya agar ekstubasi berjalan mulus tetapi juga menghindari pasien mengalami gejala Parkinson setelah emergence.

Interaksi alat dengan sistem DBS

Selama pembedahan sistem DBS berpotensi berinteraksi dengan berbagai alat medis, termasuk diatermi, elektrokauter, stimulator saraf tepi, defibrilator jantung eksternal, ultrasound terapetik dan peralatan laser. Beberapa alat ini menimbulkan gangguan elektromagnetik yang berpotensi mempengaruhi fungsi neurostimulator, yang pada akhirnya membahayakan pasien. Sebagai contoh, gangguan elektromagnetik dapat menyebabkan kerusakan langsung pada IPG, yang dapat mengakibatkan penurunan atau peningkatan rangsangan atau tidak ada output sama sekali.1 Selain itu, arus yang timbul dapat melewati IPG sepanjang kabel penghubung, menyebabkan pembentukan panas pada ujung elektrode DBS dan menyebabkan kerusakan jaringan otak yang berada dekat dengan elektrode.1 Bahkan ketika neurostimulator dimatikan, kotak logamnya, sandapannya dan unit DBS sendiri tetap bersifat konduktif, memungkinkan arus untuk lewat. Tabel 4 menjabarkan interaksi-interaksi alat ini dan penanganan untuk tiap interaksi.

\section{Elektrokardiogram (EKG)}

DBS dapat menyebabkan artefak pada elektrokardiogram (EKG) dan menyebabkan interpretasi menjadi sulit. ${ }^{8}$ Menginaktifkan sistem DBS sebelum pemasangan EKG dapat menyingkirkan gangguannya, namun dapat menyebabkan kembalinya tremor berat dengan aktivitas elektromiografi yang dapat mengganggu perekaman EKG dan ketidaknyamanan pasien.

\section{Diatermi, elektrokauter, pembedahan elektrik}

Ketiga terminologi ini sering digunakan secara bergantian, tetapi sebenarnya terdapat perbedaan di antara ketiga istilah ini. Secara khusus, diatermi adalah pembangkitan panas di dalam jaringan tubuh dari arus elektromagnetik berfrekuensi tinggi. Fisioterapis, chiropractor dan terapis cedera olahraga sering menggunakan teknik ini untuk relaksasi otot dan terapi sendi. ${ }^{11}$ Diatermi tidak boleh digunakan pada pasien dengan sistem DBS tertanam. Energi dari diatermi dapat ditransfer melalui sistem DBS tertanam (atau komponen tertanam secara terpisah) yang dapat menyebabkan sistem DBS terstimulasi ataupun kerusakan jaringan yang dapat menyebabkan cedera parah atau bahkan kematian. Alat-alat ini (baik diatermi ultrasonik gelombang pendek 
Tabel 2. Garis Besar Penanganan Anestesia pada Pasien dengan Alat DBS yang menjalani Pembedahan

\section{Pra Bedah}

1. Nilai pasien untuk indikasi pemasangan DBS, optimalisasi masalah-masalah medis (misal penyakit jantung iskemik, diabetes) dan pengobatan yang sedang dijalani

2. Dapatkan informasi mengenai alat DBS dari pasien, kartu informasi DBS atau dokter yang merawat.10

a. model DBS, lokasi IPG, tanggal terakhir diperiksa dan baterai diganti oleh dokter yang merawat

b. pengaturan arus, kemungkinan diprogram dan komplikasi alat sebelumnya

c. tingkat keparahan keluhan bila alat dimatikan

d. pelajari penggunaan pemrogram pasien, terutama bagaimana menyalakan dan mematikan alat

3. Diskusi dengan ahli penyakit saraf pasien atau dokter DBS untuk hal-hal penting yang perlu diperhatikan dan penilaian pasca bedah baik untuk pasiennya maupun untuk alatnya10

4. Foto toraks untuk mengidentifikasi jalur kabel DBS untuk mencegah kerusakan selama pembedahan yang dekat dengan alat dan untuk identifikasi tipe dan pembuat alat

5. Atur dengan teknisi atau dokter DBS untuk konsultasi dan pengaturan DBS

Selama Pembedahan

1. Matikan alat DBS untuk meminimalisir gangguan elektromagnetik:1

a. Model DBS yang lebih tua (misal Medtronic Kinetra ${ }^{\circledR}$ Model 7428 , Medtronic Soletra ${ }^{\circledR}$ Model 7426) harus diturunkan dayanya terlebih dahulu (pindah amplitudo ke $0 \mathrm{~V}$ ) sebelum dimatikan1

b. Matikan alat DBS setelah induksi anestesi umum bila gejala yang kambuh berat

c. Selama anestesi regional, tingkatkan sedasi bila gejala berat

d. Untuk pembedahan darurat dan pemrogram tidak ada, lanjutkan ke hal-hal yang diperhatikan untuk elektrokauter

e. Nyalakan alat DBS sebelum pasien dibangunkan dan emergence

2. Hal-hal yang perlu diperhatikan untuk elektrokauter: 1

a. Gunakan mode kauter bipolar dengan pengaturan daya minimum. Gunakan secara singkatsingkat dan tidak beraturan

b. Bila mode kauter unipolar yang digunakan, letakkan grounding pad sedemikian rupa sehingga jalur arus di antara elektrode aktif dari unit elektro-bedah dan bantalan tersebut tidak melewati sistem DBS

\section{Pascabedah}

1. Lakukan pemeriksaan neurologis untuk menyingkirkan efek samping terkait interaksi alat

2. Alat DBS diperiksa oleh teknisi atau dokter DBS

Dikutip dari Yeoh TY, Manninen P, Kalia SK, Venkatraghavan L. Anesthesia considerations for patients with an implanted deep brain stimulator undergoing surgery: a review and update. J Can Anesth 2017; 64: 308-19.

maupun terapetik) dapat menyebabkan kerusakan meskipun tidak terbentuk panas. Elektrokauter adalah pembangkitan panas di dalam elektrode kabel logam dengan mengalirkan arus melaluinya; arus ini umumnya tidak masuk ke dalam tubuh pasien. ${ }^{11}$ Elektrokauter umumnya digunakan untuk menghentikan perdarahan jaringan atau berbagai tingkat destruksi jaringan, misalnya eksisi lesi kulit yang jinak. Pembedahan elektrik umumnya digunakan selama pembedahan dan meliputi kisaran modalitas menggunakan arus alternatif berfrekuensi tinggi pada ujung elektrode untuk memotong, koagulasi atau mengeringkan jaringan. ${ }^{11}$ Secara umum, unit pembedahan elektrik terdiri dari dua konfigurasi electrode berbeda, yaitu unipolar dan bipolar. Pada model unipolar, arus dibangkitkan melalui elektrode masuk ke dalam tubuh pasien dan sirkuit listrik menjadi lengkap ketika arus mencapai bantalan ground. Sebaliknya, aliran listrik pada model bipolar terbatas pada jaringan di antara dua eleckrode dari unit pembedahan elektrik. Model bipolar ini dinyatakan lebih aman digunakan pada pasien dengan neurostimulator tertanam. ${ }^{12}$ Terdapat laporan kasus pasien dengan neurostimulator tertanam yang mengalami cedera 
otak serius karena pembangkitan panas pada ujung elektrode DBS setelah penggunaan diatermi untuk terapi gigi. ${ }^{13}$ Pabrik pembuatnya setelahnya mengeluarkan saran produk untuk berhatihati terhadap penggunaan semua bentuk terapi diatermi pada pasien dengan neurostimulator.

\section{Stimulator Saraf Tepi}

Penggunaan stimulator saraf tepi telah dilaporkan aman pada pasien dengan alat DBS dan pada saat pelaksanaan blok dengan panduan stimulator saraf, generator DBS dibiarkan menyala selama prosedur. ${ }^{14}$ Kewaspadaan keamanan diperlukan dalam prosedur-prosedur ini termasuk memastikan jalur stimulasi listrik tidak melewati sistem DBS dan bahwa tempat suntikan tidak di dekat kabel-kabel alat DBS. ${ }^{10}$ Sebagai alternatif, melakukan blok regional dengan panduan USG menghilangkan interaksi potensial antara stimulator saraf tepi dengan alat DBS.

\section{Alat Ultrasonik, Terapi Radiasi, Laser}

Ultrasound makin banyak digunakan sebagai modalitas terapi karena kemampuannya membangkitkan efek seperti panas dan stres mekanik. ${ }^{15}$ Teknologi ini umumnya digunakan selama fakoemulsifikasi untuk pembedahan katarak, litotripsi ekstrakoporeal untuk pengambilan batu ginjal dan scalpel harmonik untuk pemotongan dan kauterisasi bedah. Ultrasound diagnostik dapat dikerjakan secara aman pada pasien dengan neurostimulator tetapi pabrik pembuat merekomendasikan agar transducer tidak diletakkan langsung di atas alat DBS. Penggunaan fakoemulsifikasi untuk operasi katarak telah dilaporkan aman pada beberapa kasus. Litotripsi tidak direkomendasikan oleh pabrik karena potensi kerusakan sirkuit neurostimulator karena frekuensi ultrasonik yang high output. Namun demikian penggunaannya bukan merupakan kontraindikasi dan bila litotripsi harus dilakukan, berkas sinarnya sebaiknya tidak diarahkan dalam kisaran $15 \mathrm{~cm}$ dari neurostimulator. ${ }^{1}$

Terapi radiasi sebaiknya tidak diberikan di sekitar alat DBS. Bila diberikan pun, jumlah paparannya harus dibatasi dan perisai timbal harus digunakan untuk melindungi alat dan alat harus diperiksa setelah setiap terapi. Serupa, bila terapi laser digunakan, neurostimulator harus dimatikan dan laser diarahkan jauh dari alat. Karena hanya terdapat sedikit data keselamatan pada penggunaan alat-alat medis di atas pada pasien dengan neurostimulator, indikasi penggunaannya harus dipertimbangkan secara hati-hati dan risiko harus didiskusikan secara mendetil dengan pasien. Langkah kewaspadaan umum di antaranya mengarahkan alat jauh dari neurostimulator bila digunakan, mematikan alat DBS selama prosedur dan memeriksa alat setelah prosedur.

\section{Defibrilator Jantung Eksternal}

Defibrilator jantung eksternal dan kardioversi sifatnya menyelamatkan nyawa dan oleh karenanya penggunaannya tidak boleh dihalangi pada pasien dengan alat DBS. Sebuah laporan kasus menunjukkan bahwa karioversi eksternal dengan $300 \mathrm{~J}$ tidak memberikan efek pada fungsi sistem DBS. Untuk meminimalisir kerusakan pada sistem DBS, direkomendasikan untuk menggunakan pengaturan output sekecil mungkin dan memposisikan paddle sejauh mungkin dari neurostimulator dan tegak lurus terhadap sistem DBS. Setelahnya pun, neurostimulator harus diperiksa.

\section{Alat Pacu Jantung (pacemaker) dan ICD}

Pemasangan alat pacu jantung dan/atau ICD pada pasien dengan neurostimulator dan sebaliknya, bukan merupakan kontraindikasi dan telah dilakukan dengan sukses.1 Namun demikian, interaksi antara alat-alat ini masih mungkin terjadi, termasuk penginderaan takiaritmia yang tidak tepat oleh ICD dan dapat menyebabkan pelepasan syok dan inaktivasi atau pengaturan yang berubah pada neurostimulator.1 Penilaian pra bedah menyeluruh oleh tim multidisplin (ahli jantung, ahli DBS dan ahli anestesiologi) perlu dilakukan untuk mengoptimalkan status klinis pasien dan mengatur alat medis dasar sesuai kebutuhan. Untuk meminimalisir interaksi antara alat pacu jantung dan alat DBS, alat pacu jantung harus diprogram ke bipolar sensing mode untuk mencegah penginderaan dan respons yang tidak tepat. ${ }^{16}$

Serupa, penggunaan bipolar sensing electrode 
Tabel 3. Daftar Tilik Evaluasi Prabedah Pasien dengan Deep Brain Stimulator

Penilaian alat secara umum

- Pembuat teridentifikasi

- Model teridentifikasi

- Nomer model teridentifikasi

- Usia baterai mencukupi

- Integritas baik

Pertimbangan spesifik Pasien

- Indikasi pemasangan DBS teridentifikasi

- Keparahan gejala penyakit ketika DBS dinonaktifkan telah dinilai

- Lokasi persis komponen DBS telah diketahui

Bila tidak, harus dilakukan pemeriksaan radiologi yang memadai

- $\quad$ EKG dengan DBS telah tercatat tidak terganggu

Bila tidak, dilakukan EKG pra bedah untuk menilai adanya gangguan

Bila EKG dengan DBS dinilai terganggu berat, dilakukan optimalisasi pengaturan oleh pengatur DBS primer

- $\quad$ Bila pasien memiliki pengontrol pribadi, telah diinstruksikan untuk dibawa

- Bila antikoagulan perioperatif diperlukan, pengatur DBS primer telah diberi tahu

Komunikasi tenaga kesehatan

- $\quad$ Pengatur DBS primer mengetahui:

Bila digunakan MRI:

Ahli radiologi mengetahui

Teknisi radiologi mengetahui

- Bila digunakan elektrokauter, defibrilator, pacemaker, ECT atau fakoemulsifikasi atau DBS dinonaktifkan:

Tim bedah mengetahui

Tim anestesia mengetahui

Tim perawat mengetahui

Wakil pembuat dikontak untuk pengaturan

Dikutip dari Weinstein AS, Aglio LS. Preanesthetic evaluation of a patient with a deep brain stimulator: a practical guide and checklist for patient safety. JCA 2016;31:278-281.

untuk sistem ICD juga menurunkan penginderaan berlebih. Selain itu, pelepasan energi ICD sampai dengan $35 \mathrm{~J}$ tampaknya tidak akan memberikan efek pada fungsi alat DBS, meskipun ada sebuah kasus yang melaporkan pelepasan syok menyebabkan penurunan luaran generator ke kondisi 'off' dengan amplitude 0 V.1 Oleh karenanya, fungsi neurostimulator harus diperiksa setelah ICD menghantarkan syok. Untuk mengurangi gangguan elektromagnetik, direkomendasikan untuk tidak meletakkan IPG dari dua sistem secara berdekatan. ${ }^{16}$ Magnet dapat mengganggu fungsi dan pemrograman baik IPG jantung maupun neurostimulator, dan penggunaannya harus dihindari, untuk mencegah pemrograman ulang atau terhentinya alat-alat ini secara tidak sengaja. Sebaliknya, pemrogram telemetrik yang spesifik harus digunakan untuk pemrograman alat. Bila magnet eksternal diperlukan selama pembedahan untuk menonaktifkan fungsi defibrilator dari ICD, hati-hatilah untuk tidak meletakkannya dekat dengan alat DBS. Pada akhirnya, pemeriksaan jantung mendetil, yaitu monitoring Holter, harus dilakukan bila dilakukan pengaturan kembali pada alat DBS untuk memastikan fungsi alat pacu jantung berfungsi secara konsisten. ${ }^{16}$

\section{Anestesia Regional}

Pada pasien dengan gangguan pergerakan, menginaktifkan alat DBS dapat menyebabkan kembalinya gejala yang mungkin lebih parah dibandingkan gejala basalnya. Hal ini merupakan tantangan baik bagi pasien maupun ahli bedah selama prosedur yang dilakukan dengan anestesia regional. Memberikan sedasi yang adekuat 
Tabel 4. Interaksi Alat dengan Sistem DBS dan Penanganannya

\begin{tabular}{|c|c|c|}
\hline & Interaksi potensial & Tindakan antisipatif \\
\hline Diatermi & $\begin{array}{l}\text { Pemanasan pada ujung elektrode } \\
\text { DBS }\end{array}$ & Merupakan kontraindikasi \\
\hline $\begin{array}{l}\text { Elektrokauter/ } \\
\text { pembedahan } \\
\text { elektrik }\end{array}$ & $\begin{array}{l}\text { Kerusakan pada IPG } \\
\text { menyebabkan peningkatan } \\
\text { atau penurunan stimulasi } \\
\text { atau inaktivasi alat } \\
\text { Pemanasan pada ujung } \\
\text { elektrode DBS }\end{array}$ & $\begin{array}{l}\text { Matikan DBS. Gunakan kauter bipolar dengan } \\
\text { pengaturan daya minimal. Gunakan secara tidak } \\
\text { beraturan dan singkat-singkat. Bila kauter unipolar } \\
\text { digunakan, letakkan bantal ground sedemikian rupa } \\
\text { sehingga jalur arus antara elektrode kauter dan bantal } \\
\text { tidak melalui sistem DBS }\end{array}$ \\
\hline
\end{tabular}

Stimulator saraf tepi

Dilaporkan aman tetapi harus hati-hati

Pastikan jalur stimulasi tidak melewati sistem DBS. Lakukan pemeriksaan foto toraks untuk identifikasi jalur kabel alat DBS untuk menghindari kerusakan. Pastikan titik suntik tidak dekat dengan kabel alat DBS

Ultrasound

- Ultrasound diagnostik aman

- Jangan letakkan transducer langsung di atas DBS

- Potensial interaksi dengan ultrasound terapetik, misalnya litotripsi

- Mungkin merusak sistem DBS

Defibrilator Kerusakan sistem DBS

jantung eksternal

- Matikan DBS. Jangan meletakkan kepala instrumen ultrasound dalam jarak $15 \mathrm{~cm}$ dari alat DBS

- Jangan berikan radiasi di dekat alat DBS. Lindungi alat DBS dengan perisai timbal dan batasi jumlah paparan. Periksa alat DBS setelah tiap terapi

Posisikan paddle defibrilator sejauh mungkin dari DBS. Posisikan paddle tegak lurus terhadap sistem DBS. Gunakan pengaturan output sekecil mungkin. Cek fungsi DBS setelah defibrilasi

$\begin{array}{lll}\text { Elektrokardiogram } & \text { Artefak pada perekaman EKG } \\ \text { Pacemaker } & \text { - } & \text { Deteksi dan respons } \\ \text { jantung dan ICD } & \text { pacemaker tidak tepat } \\ & \text { Deteksi takiaritmia dan } \\ & \text { pelepasan ICD tidak tepat } \\ & \text { Pemrograman ulang atau } \\ & \text { inaktivasi DBS }\end{array}$

Matikan DBS

MRI

- Kerusakan pada IPG dan pemanasan ujung elektrode

- Artefak dan distorsi gambar

Terapi

- Mungkin menyebabkan - Matikan DBS

elektrokonvulsif kerusakan sistem DBS.
Pemanasan pada ujung elektrode

- $\quad$ Pergeseran elektrode karena kejang

- Konsul ahli jantung dan dokter DBS

- Pemrograman pacemaker dan/atau ICD diatur pada mode deteksi bipolar. Letakkan IPG kedua alat sejauh mungkin satu dari yang lain. Periksa fungsi DBS bila syok diberikan oleh ICD. Lakukan monitoring Holter setelah menyesuaikan pengaturan DBS

Bergantung model. Baca kembali panduan pabrik yang relevan

Matikan DBS eketrode DBS

- Gunakan energi sekecil mungkin untuk induksi kejang

Dikutip dari Yeoh TY, Manninen P, Kalia SK, Venkatraghavan L. Anesthesia considerations for patients with an implanted deep brain stimulator undergoing surgery: a review and update. J Can Anesth 2017; 64: 308-19.

mungkin dapat membantu mengurangi gejala dan memungkinkan kondisi pembedahan. Sedasi yang dapat dilakukan di antaranya midazolam (0,5-1 mg iv), pemberian propofol kontinu (25$75 \mathrm{mcg} / \mathrm{kg} / \mathrm{menit} \mathrm{iv})$ dan dexmedetomidine $(0,2-$
$0,7 \mathrm{mcg} / \mathrm{kg} / \mathrm{jam}$ iv) dan obat-obatan ini harus dititrasi sesuai respons pasien secara individual. ${ }^{1}$ Risiko perioperatif infeksi terkait perangkat keras Angka kejadian infeksi terkait-perangkat-keras setelah pemasangan DBS (pemasangan primer 
dan/atau penggantian IPG) bervariasi antara $0-15 \% .{ }^{17}$ Variasi yang lebar ini sekunder karena perbedaan definisi infeksi perangkat keras, periode tindak lanjut setelah pemasangan dan perhitungan angka kejadian infeksi berdasar jumlah pasien atau prosedur. Staphylococcus aureus adalah mikroorganisme yang paling sering ditemukan pada kultur. ${ }^{17}$ Saat ini belum ada panduan pasti mengenai terapi infeksi terkaitperangkat keras setelah pemasangan DBS, namun demikian piihan terapi di antaranya terapi antibiotika dengan atau tanpa pengeluaran alat secara sebagian/seluruhnya. ${ }^{17}$

Data mengenai peningkatan risiko infeksi perangkat keras pada pasien dengan sistem DBS yang menjalani pembedahan tak terkait (yaitu pembedahan yang tidak terkait dengan pemasangan atau penggantian IPG) juga sangat sedikit. Lebih jauh lagi, panduan berbasis bukti untuk terapi antibiotika spesifik juga tidak tersedia. Dalam kondisi seperti ini, rekomendasi mengenai terapi antibiotika spesifik tidak dapat ditetapkan dan protokol cenderung bervariasi antara pusat yang satu dengan pusat lainnya. Pada kasus-kasus di mana pembedahan yang akan dilakukan jauh dari perangkat keras, profilaksis antibiotika rutin untuk pembedahan tersebut kemungkinan besar sudah cukup. Sedangkan pada kasus di mana pembedahan yang akan dilakukan melibatkan membuka kembali ruang tempat perangkat keras DBS ditanam, maka konsultasi harus dilakukan dengan tim bedah DBS. Bila pasien mengalami infeksi pada tempat pembedahan dan/atau mengalami sepsis, baik tim bedah DBS dan dokter penyakit infeksi harus dilibatkan untuk memberikan terapi yang sesuai. ${ }^{17}$

\section{Pertimbangan Pascabedah}

Pada akhir prosedur, neurostimulator harus diaktifkan kembali ke pengaturan asal. Bila dilakukan anestesi umum, sebaiknya alat diaktifkan sebelum pasien dibangunkan untuk menghindari kembalinya gejala ketika pasien bangun. ${ }^{12}$

\section{Prosedur Non Bedah}

Magnetic Resonance Imaging (MRI)

Penggunaan MRI pada pasien dengan alat DBS dulunya merupakan kontraindikasi absolut karena interaksi elektromagnetik yang berpotensi menyebabkan morbiditas pasien. Sistem MRI menghasilkan tiga tipe medan elektromagnetik: 1) medan magnet statis yang selalu ada secara konstan, 2) medan magnet gradien yang hanya ada selama proses pemindaian dan 3) medan radiofrekuensi (RF) yang ada hanya pada waktu pemindaian dan dihasilkan oleh berbagai transmisi kumparan RF. ${ }^{18}$

Pertimbangan keselamatan dengan MRI di antaranya pemanasan berlebih pada ujung elektrode alat DBS karena penumpukan arus yang dihasilkan oleh medan magnet gradien dan RF selama sistem DBS, interaksi meadan magnet, artefak dan distorsi gambar serta gangguan fungsi sistem DBS. ${ }^{18}$ Jumlah panas yang dihasilkan dalam sistem DBS bergantung pada beberapa faktor, termasuk kondisi listrik alat neurostimulator, kekuatan medan dari sistem MRI, posisi komponen DBS terhadap sumber energi RF, tipe kumparan RF yang digunakan, titik pencitraan dan kecepatan absorpsi spesifik (specific absorption rate - SAR). ${ }^{1}$ SAR adalah pengukuran kecepatan energi yang diabsorbsi oleh tubuh manusia bila terpapar oleh medan elektromagnetik RF dan parameter ini sering digunakan untuk mengidentifikasi batasan keselamatan MRI. Morbiditas yang cukup serius namun bersifat sementara dilaporkan pada 2 kasus. Pada kasus pertama, pasien dengan sistem DBS STN (subthalamic nuclei) bilateral mengalami gerakan distonik dan balistik unilateral yang berlangsung beberapa minggu setelah MRI kepala. Kasus kedua mengenai seorang pasien dengan DBS STN bilateral yang menjadi hemiplegi setelah MRI lumbal. Pencitraan selanjutnya menggambarkan perdarahan subakut dekat dengan ujung elektrode DBS. ${ }^{18}$

Beberapa neurostimulator kompatibel dengan MRI, seperti ditunjukkan oleh beberapa laporan yang menunjukkan penggunaan MRI aman dalam kondisi tertentu pasien dengan sistem DBS. Dengan kemajuan teknologi DBS, beberapa pusat sekarang secara rutin melakukan pemasangan DBS dengan panduan MRI intraoperatif. Panduan spesifik penggunaan MRI pada pasien 
yang terpasang sistem DBS bervariasi tergantung pabrik pembuat. Sebagai contoh, penggunaan MRI saat ini merupakan kontraindikasi untuk sistem DBS Boston Scientific1 tetapi dapat dilakukan, bila perlu, pada pasien dengan sistem DBS Medtronic dalam kondisi tertentu. Sebelum MRI, dokter yang merawat harus mengetahui model neurostimulator yang tertanam, ada tidaknya pocket adaptor yang tertanam, status sandapan implan (internalisasi atau eksternalisasi) dan integritas sistem (kerusakan dalam sistem merupakan tempat potensial untuk menghasilkan panas berlebih), karena faktorfaktor ini menentukan apakah sistem DBS memungkinkan pemindaian seluruh tubuh atau hanya kepala. Secara umum, pasien dengan model neurostimulator yang menggunakan saklar magnetis atau sistem DBS dengan pocket adaptor atau sandapan eksternal hanya memungkinkan untuk dilakukan pemindaian kepala saja.

Ketika kelayakan MRI telah dipastikan, pemindaian hanya dapat dilakukan dengan beberapa kondisi tertentu. Sampai dengan saat ini, hanya sistem MRI 1.5 Tesla horizontal closed bore/64 MHz RF yang telah menunjukkan aman digunakan pada pasien dengan implan neurostimulator. Profil keamanan pada medan magnet statis tertentu tidak dapat diekstrapolasikan pada sistem yang lain, meskipun pada sistem dengan kekuatan medan yang lebih kecil. ${ }^{1}$ Neurostimulator harus dinonaktifkan selama pencitraan, yang mana pada beberapa pasien dapat menyebabkan munculnya kembali gejala yang mengganggu keakuratan gambar. Pada sistem neurostimulator dengan saklar magnetis, saklar magnetis harus dinonaktifkan dan amplitudo stimulasi diatur pada posisi $0 \mathrm{~V}$. Kewaspadaan keamanan lainnya di antaranya membatasi waktu pemindaian aktif, pasien diposisikan dengan tepat dan komunikasi konstan dengan pasien untuk mengidentifikasi terjadinya komplikasi secara dini. Setelah pencitraan, ahli DBS harus melakukan pemeriksaan terhadap neurostimulator dan mengaktifkan alat tersebut ke pengaturan asal.

Terapi Elektrokonvulsif (ECT)

Pertimbangan keselamatan melakukan ECT pada pasien dengan neurostimulator termasuk pembentukan panas pada elektrode DBS dari induksi arus RF oleh beban elektrik, kerusakan fungsi sistem DBS dan bergesernya elektrode karena aktivitas kejang.1 Beberapa kasus telah menunjukkan amannya dilakukan ECT dengan tindakan antisipatif berikut ini: menonaktifkan neurostimulator, meletakkan elektrode ECT sejauh mungkin dari elektrode DBS dan penggunaan energi sekecil mungkin untuk induksi kejang. ${ }^{18}$

\section{Simpulan}

Teknologi deep brain stimulation telah berkembang pesat dalam waktu 25 tahun terakhir. DBS kini merupakan standar perawatan pasien dengan berbagai kondisi nerurologis dan ahli anestesi akan lebih sering menghadapi pasien dengan alat ini. Oleh karenanya, penting bagi ahli anestesi untuk mengetahui hal-hal yang berkaitan untuk mencegah bahaya pada pasien. Prinsip penanganan anestesi di antaranya adalah identifikasi jenis alat, melibatkan ahli DBS untuk kewaspadaan tertentu dan penanganan alat, menonaktifkan alat DBS intraoperatif, mengambil tindakan-tindakan antisipatif untuk penggunaan aman alat-alat listrik pada pembedahan dan memeriksa kembali alat pada periode pascabedah.

\section{Daftar Pustaka}

1. Yeoh TY, Manninen P, Kalia SK, Venkatraghavan L. Anesthesia considerations for patients with an implanted deep brain stimulator undergoing surgery: a review and update. J Can Anesth 2017; 64: 308-19.

2. Benabid AL, Pollak P, Louveau A, Henry S, de Rougemont J. Combined (thalamotomy and stimulation) stereotactic surgery of the VIM thalamic nucleus for bilateral Parkinson disease. Appl Neurophysiol 1987; 50: 344-6.

3. Venkatraghavan L, Maninnen P. Anesthesia for deep brain stimulation. Curr Opin Anaesthesiol 2011; 24: 495-9.

4. Lozano AM, Lipsman N. Probing and 
regulating dysfunctional circuits using deep brain stimulation. Neuron 2013; 77: 406-24.

5. Lempka SF, Johnson MD, Miocinovic S, Vitek JL, McIntyre CC. Current-controlled deep brain stimulation reduces in vivo voltage fluctuations observed during voltagecontrolled stimulation. Clin Neurophysiol 2010; 121: 2128-33.

6. Miocinovic S, Somayajula S, Chitnis S, Vitek JL. History, applications, and mechanisms of deep brain stimulation. JAMA Neurol 2013; 70: 163-71.

7. American Society of Anesthsiologists. Practice advisory for the perioperative management of patients with cardiac implantable electronic devices: pacemakers and implatable cardioverter-defibrillators: an updated report by the American Society of Anesthesiologists Task Force on Perioperative Management of Patients with Cardiac Implantable Electronic Devices. Anesthesiology 2011; 114: 247-61.

8. Poon CC, Irwin MG. Anaesthesia for deep brain stimulation and in patients with implanted neurostimulator devices. $\mathrm{Br} \mathrm{J}$ Anaesth 2009; 103: 152-65.

9. Venkatraghavan L, Luciano M, Manninen P. Review article: anesthetic management of patients undergoing deep brain stimulator insertion. Anesth Analg 2010; 110: 1138-45.

10. Venkatraghavan L, Chinnapa V, Peng P, Brull R. Non-cardiac implantable electrical devices: brief review and implications for anesthesiologists. Can J Anesth 2009; 56: $320-6$.

11. Riordan AT, Gamache C, Fosko SW. Electrosurgery and cardiac devices. J Am Acad Dermatol 1997; 37: 250-5.
12. Khetarpal M, Yadav M, Kulkarni D, Gopinath R. Anaesthetic management of a patient with deep brain stimulation implant for radical nephrectomy. Indian J Anaesth 2014; 58: 461-3.

13. Nutt JG, Anderson VC, Peacock JH, Hammerstad JP, Burchiel KJ. DBS and diathermy interaction induces severe CNS damage. Neurology 2001; 56: 1384-6.

14. Gandhi R, Chawla R. Anaesthetic management of shoulder arthroscopic repair in Parkinson's disease with deep brain stimulator. Indian J Anaesth 2014; 58: 309-11.

15. Miller DL, Smith NB, Bailey MR, Czarnota GJ, Hynynen K, Makin IRS. Overview of therapeutic ultrasound applications and safety considerations. J Ultrasound Med 2012; 31: 623-34.

16. Capelle HH, Simpson RK, Kronenbuerger M, Michaelsen J, Tronnier V, Krauss JK. Longterm deep brain stimulation in elderly patients with cardiac pacemakers. J Neurosurg 2005; 102: 53-9.

17. Bjerknes S, Skogseid IM, Soehle T, Dietrichs E, Toft M. Surgical site infections after deep brain stimulation surgery: frequency, characteristics and management in a 10-year period. PLoS One 2014; 9: e105288.

18. Kahan J, Papadaki A, White M, Mancini L, Yousry T, Zrinzo L, dkk. The safety of using body-transmit MRI in patients with implanted deep brain stimulation devices. PLoS One 2015; 10: e0129077.

19. Weinstein AS, Aglio LS. Preanesthetic evaluation of a patient with a deep brain stimulator: a practical guide and checklist for patient safety. JCA 2016;31:278-81. 